\title{
Classification of Symptomatic Chiari I Malformation to Guide Surgical Stategy
}

\author{
Mohammed F. Shamji, Enrique C.G. Ventureyra, Benedicto Baronia, \\ Munyao Nzau, Michael Vassilyadi
}

\begin{abstract}
Background: Treatment options for Chiari I malformations include posterior fossa decompression (PFD) with additional techniques including laminectomy, intradural exploration, and duraplasty. Neuroimaging findings of cisterna magna volume, syringomyelia, and intraoperative ultrasonography may tailor surgical intervention. Methods: We developed an algorithm classifying symptomatic Chiari I patients into three groups to define minimum operation. Without syringomyelia, the presence of cisterna magna defined Group A and the absence defined Group B. Patients with syrinx formed Group C. Mild structural pathology (Group A) or adequate space following PFD (Group B, normal intraoperative ultrasound (IOUS)) should be treated by PFD alone. Conversely, presence of syringomyelia (Group C) or inadequate space following PFD (Group B, abnormal IOUS) should additionally have duraplasty. We applied this algorithm to patients treated at a single institution over 16 years. Results: Twenty-four symptomatic Chiari I malformation patients were divided into three groups that did not differ by age, gender, or extent of tonsillar ectopia. All patients treated by this algorithm experienced clinical and radiographic improvement. This included eight Group B patients who underwent PFD only $(n=6)$ or additional duraplasty $(n=2)$ decided by IOUS. Conclusion: Treatment of symptomatic Chiari I malformation may have inadequate outcome with conservative strategy or complications with aggressive strategy. This algorithm utilizes preoperative neuroimaging and intraoperative ultrasound to tailor intervention, with excellent clinical outcome and radiographic syrinx resolution on application to 24 patients. Further validation requires prospective multicenter evaluation with larger patient population.
\end{abstract}

RÉSUMÉ: Classification de la malformation de Chiari de type 1 symptomatique pour guider la stratégie chirurgicale. Contexte : Les options de traitement des malformations de Chiari de type 1 incluent la décompression de la fosse postérieure (DFP) et certaines techniques comme la laminectomie, l'exploration intradurale et la plastie de la dure-mère. L'intervention chirurgicale peut être modifiée selon les observations du volume de la citerne cérébello-médullaire et de la syringomyélie faites à la neuroimagerie et les observations faites à l'échographie peropératoire (EPO). Méthodes : Nous avons développé un algorithme pour classifier les patients atteints de Chiari de type 1 symptomatique en trois groupes afin de définir l'intervention minimale. En l'absence de syringomyélie, la présence de la citerne cérébello-médullaire est caractéristique du groupe A et son absence est caractéristique du groupe B. Les patients qui ont un syrinx constituent le groupe $\mathrm{C}$. Ceux qui ont une pathologie structurale légère (groupe A) ou un espace adéquat après la DFP (groupe $\mathrm{B}$, EPO normale) devraient être traités seulement par la DFP, contrairement à ceux qui ont une syringomyélie (groupe C) ou un espace inadéquat suite à la DFP (groupe B, EPO anormale) devraient subir une plastie de la dure-mère. Nous avons utilisé cet algorithme chez des patients traités dans la même institution au cours d'une période de 16 ans. Résultats : Vingt-quatre patients atteints d'une malformation de Chiari de type 1 symptomatique ont été divisés en trois groupes dont la répartition selon l'âge, le sexe et l'étendue de l'ectopie amygdalienne était la même. Tous les patients traités selon cet algorithme ont eu une amélioration clinique et radiologique, dont 8 patients du groupe $\mathrm{B}$ qui ont subi seulement une DFP $(\mathrm{n}=6)$ ou une DFP avec plastie de la dure-mère $(\mathrm{n}=2)$ sur la base de l'EPO. Conclusion : Le résultat du traitement de la malformation de Chiari de type 1 symptomatique peut être inadéquat si une stratégie conservatrice est utilisée ou s'il survient des complications si une stratégie agressive est utilisée. Cet algorithme utilise la neuroimagerie préopératoire et l'échographie peropératoire pour adapter l'intervention. Le résultat clinique et la résolution du syrinx radiologique ont été excellents chez ces 24 patients. Cet algorithme devrait faire l'objet d'une évaluation multicentres comportant un plus grand nombre de patients pour le valider.

Can. J. Neurol. Sci. 2010; 37: 482-487

Hans Chiari ${ }^{1}$ first described the caudal displacement of the cerebellar tonsils in 1891 and such abnormality is frequently identified in both young adult and pediatric patients. Clinical presentation can be very variable, ranging from asymptomatic incidental abnormality discovered by imaging for other indications to symptoms arising from raised intracranial pressure, brainstem compression, cerebellar dysfunction, or concomitant spinal cord syrinx. Neuroimaging findings for Chiari I malformation have typically revealed descent of the cerebellar tonsils by $5 \mathrm{~mm}$ beyond the foramen magnum into the spinal canal. However, the putative pathoembryology of an underdeveloped para-axial mesoderm ${ }^{2,3}$ has lead several authors to describe the smaller size of the posterior fossa and steeper tentorial slope in affected patients than age-matched controls. ${ }^{4-6}$ Neither measure, however, correlated well with the presence or severity of symptoms.

From the Division of Neurosurgery (MFS, ECGV, MN, MV), The Ottawa Hospital; Division of Neurosurgery (ECGV, BB, MN, MV), Children's Hospital of Eastern Ontario, Ottawa, Ontario, Canada.

Received November 23, 2009. Final Revisions Submitted January 18, 2010. Correspondence to: Enrique Ventureyra, Division of Neurosurgery, Children's Hospital of Eastern Ontario, 401 Smyth Road, Ottawa, Ontario, K1H 8L1, Canada. 
Surgical management of Chiari I malformations remains both variable and contentious, ranging from posterior fossa decompression of suboccipital craniectomy and $\mathrm{C} 1$ and $\mathrm{C} 2$ laminectomy when required ${ }^{7,8}$ to further utilization of dural splitting,,${ }^{9,10}$ tonsillar shrinkage or resection, ${ }^{11}$ duraplasty, ${ }^{12-15}$ syrinx shunting, ${ }^{16-18}$ and posterior fossa reconstruction. ${ }^{19}$ Among those patients undergoing only bony decompression, even the size of craniectomy ${ }^{19}$, the extent of laminectomy, and the need for cranioplasty ${ }^{20}$ remain controversial. Selection between these alternatives is predicated by the anatomic configuration on preoperative neuroimaging tempered by the comfort level of the attending surgeon, with comparison between case series made difficult by the heterogeneity of treatments utilized and delineation of operative extent. Indeed, surveys of general and pediatric neurosurgeons reveal little consensus on the choice of surgical strategy, including common techniques such as duraplasty and syrinx shunting. ${ }^{21,22}$ The most consistent responses were that asymptomatic patients with Chiari I malformation and no syrinx should not be treated, and that routine dural opening is recommended whenever decompression is undertaken especially in the setting of concomitant syringomyelia. The necessity of the latter technique as a matter of routine remains to be prospectively evaluated.

Spinal cord syrinx, predominantly cervical and upper thoracic, occurs in a significant fraction of patients with Chiari I malformation. ${ }^{23-26}$ Symptoms typically attributable to such pathology include disordered sensation, weakness, abnormalities of gait, scoliosis, and incontinence. It remains unclear whether the simple presence of a syrinx, and whether the patient is symptomatic from this structural lesion, should affect the type of operation performed. Both symptomatic and radiographic improvement of the syrinx are highly variably reported, ${ }^{14,16,27-29}$ and Attenello et $\mathrm{al}^{27}$ have described syrinx resolution in $55 \%$ of 49 patients treated but in only one of three patients in whom no duraplasty was performed. In contrast, Ventureyra and coworkers $^{26}$ described all patients with symptomatic Chiari I malformation and spinal cord syrinx improving following both posterior fossa decompression and duraplasty compared to only $50 \%$ improving with posterior fossa decompression alone.

Further, the utilization of intraoperative ultrasound techniques has permitted patient specific decision-making concerning the value of extending bony decompression with additional duraplasty. ${ }^{11}$ Choice between such alternatives is not benign, with duraplasty providing for potentially riskier and more complicated procedure ${ }^{10,14}$ although the choice about this technique does not represent patients with clinical equipoise and recent multivariate analysis suggests no difference in complications with or without duraplasty. ${ }^{30}$ McGirt et al ${ }^{30}$ also retrospectively question the utility of ultrasonography techniques, stating a 1.7-fold greater likelihood of treatment failure among those selected for no duraplasty, although no prospective study has yet validated those claims. Milhorat and Bolognese $^{31}$ have proposed intraoperative color Doppler ultrasonogrophy before dural opening and after dural closure to anatomically and physiologically tailor treatment to adequately decompress the cervicomedullary junction, create a retrocerebellar space of defined volume, and to confirm flow between the cranial and spinal cerebrospinal fluid (CSF) compartments.
The objective of this work was to propose a simple approach to guide the initial surgical management of Chiari I malformations based on the neuroimaging parameters including the presence of a cervical syrinx and the persistence of cisterna magna fluid space and intraoperative ultrasound findings of sufficient space and CSF flow. Such analysis integrates the parameters known to influence outcome of different surgical strategies to treat Chiari I malformations into an algorithm to guide surgical decision making for the symptomatic patient.

\section{Methods}

A retrospective review was performed of the medical records of all patients undergoing primary surgical treatment for symptomatic Chiari I malformation at the Children's Hospital of Eastern Ontario (CHEO) between January 1990 and March 2006. Patients were excluded from the analysis if they were asymptomatic from their Chiari malformation, if they had associated posterior fossa pathology causing tonsillar descent, if revision surgery was being performed, or if their chart lacked the necessary minimum six-month neuroimaging and clinical follow-up. Demographic information obtained about each patient included age, gender, and presenting symptoms. Electrophysiology results of interest included brainstem auditory evoked responses and somatosensory evoked potentials. Neuroimaging information collected included the distance of tonsillar descent, characteristics of associated syrinx (presence, location, extent), and the presence of CSF flow by cine MRI imaging.

Patients were classified into three groups based on MRI findings with the intention of guiding surgical objective, once the decision was taken that the pathology should be approached posteriorly. Group A consisted of patients in whom MRI revealed presence of a cisterna magna (volume of $8-10 \mathrm{~cm}^{3}$ ) and no evidence of a syrinx. These patients were treated by suboccipital decompression only. Group B consisted of patients in whom MRI revealed small or absent cisterna magna and no evidence of a syrinx. These patients were evaluated by intraoperative ultrasound. If the ultrasound study revealed adequate subarachnoid spaces or CSF flow, then suboccipital decompression only was performed. If the ultrasound study revealed absence of space anterior to the brainstem or posterior to the cerebellar tonsils, or if abnormal CSF flow or tonsillar piston action was observed, then the posterior fossa decompression was complemented by durotomy, arachnoid adhesiolysis, and duraplasty. Group $\mathrm{C}$ consisted of the remaining patients in whom MRI revealed a syrinx. These patients were treated by posterior fossa decompression, followed again by durotomy, arachnoid adhesiolysis, and duraplasty.

Bony decompression involved a craniectomy of approximately $3 \mathrm{~cm}$ diameter in all cases, with additional cervical laminectomy to satisfactorily decompress the ectopic tonsillar tissue (variably from no required laminectomy up to C3). When further intervention was required, the choice of expansion duraplasty material evolved over the span of this case series and included cadaveric dura, bovine pericardium, pericranium, and most recently collagen-based biomaterials. Following durotomy, the technique of arachnoid adhesiolysis involved disconnecting any adhesions between the arachnoid and the overlying dura. Attempts were made at every case to 


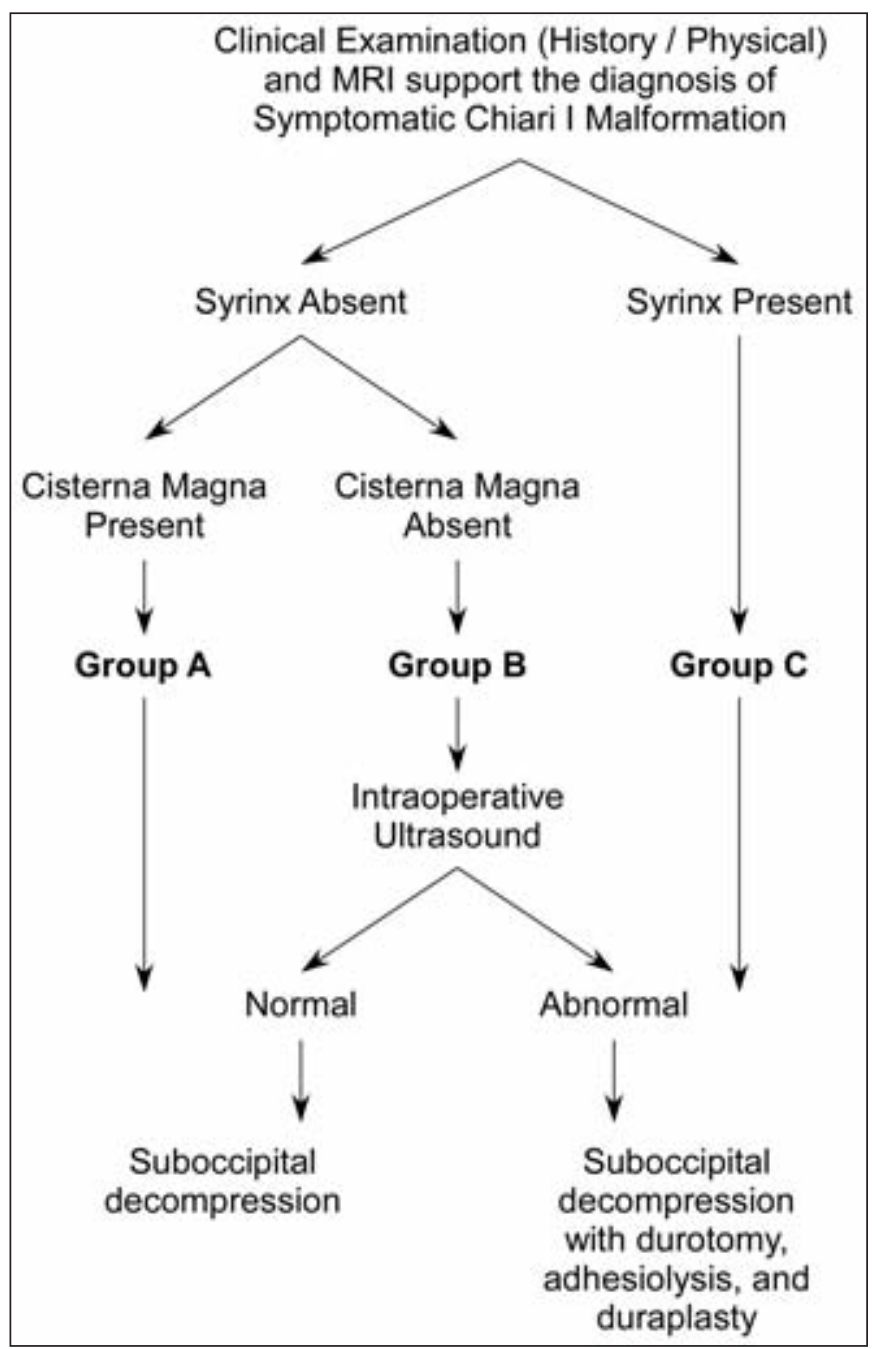

Figure: Management algorithm based on pre-operative magnetic resonance imaging and, when indicated, intraoperative ultrasound. Group A patients consist of those with no syrinx and with present cisterna magna and were treated by suboccipital decompression. Group B patients consisted of those with no syrinx and with absent cisterna magna and underwent intraoperative ultrasound to guide surgical objective. If the ultrasound was normal, revealing flow, then suboccipital decompression was performed. If the ultrasound was abnormal revealing no flow, then suboccipital decompression with duraplasty was performed. Group $C$ patients consisted of those with a syrinx and were treated by suboccipital decompression and duraplasty.

preserve the integrity of the arachnoid mater. There were no cases where entry was made into the fourth ventricle, nor where tonsillar shrinkage or resection were applied.

The classification scheme and management algorithm are summarized schematically in the Figure, and differences in patient demographics were evaluated by $\chi^{2}$ analysis with William's correction for low numbers at the 0.05 level of significance. Patients were evaluated in follow-up clinically for symptom resolution and radiographically when appropriate for syrinx resolution.

\section{RESULTS}

Fifty-two patients were identified as having Chiari I malformations, of whom 24 were selected as appropriate symptomatic patients for this study. The excluded population included 15 asymptomatic patients, eight patients with tonsillar descent secondary to posterior fossa pathology, and five symptomatic patients with unavailable neuroimaging to define their classification. The remaining patients were categorized as Group A (six patients), Group B (eight patients), and Group C (ten patients). Demographic characteristics for this study population are summarized in Table 1, stratified by the absence (Groups A and B) or presence (Group C) of a syrinx, between whom there were no differences in age or gender distribution. These groups differed by symptomatology, more frequently presenting with scoliosis among patients with syringomyelia ( $p$ $<0.01)$ and weakness among patients without syringomyelia ( $\mathrm{p}$ $=0.012$ ). Abnormal electrophysiological studies, brainstem auditory evoked responses or somatosensory evoked potentials, were observed in $64 \%$ of patients without syrinx and only $20 \%$ of patients with syrinx $(\mathrm{p}<0.01)$.

All six Group A patients underwent initial posterior fossa decompression, and uniformly experienced symptomatic improvement after the initial intervention.

Among the eight Group B patients, six underwent posterior fossa decompression and two required additional duraplasty based on unsatisfactory intraoperative ultrasound (IOUS) findings. All of these patients experienced symptomatic improvement after the initial intervention.

Among the ten Group C patients, five underwent posterior fossa decompression with duraplasty and five underwent posterior fossa decompression alone because they were treated early in this series with IOUS revealing adequate flow. Three among those five patients $(60 \%)$ underwent second operation, two with duraplasty and one with additional syringo-

Table 1: Demographic characteristics of the study patients

\begin{tabular}{|c|c|c|c|c|c|}
\hline & & $\begin{array}{c}\text { No Syrinx } \\
\text { Group A }\end{array}$ & Group B & Combined & $\begin{array}{c}\text { Syrinx } \\
\text { Group } \\
\text { C } \\
\end{array}$ \\
\hline Number & $\mathrm{N}$ & 6 & 8 & 14 & 10 \\
\hline Age & $\begin{array}{l}\text { Years - } \\
\text { mean and } \\
\text { range }\end{array}$ & $\begin{array}{l}9 \\
(1.5-18)\end{array}$ & $\begin{array}{l}8 \\
(3-15)\end{array}$ & $\begin{array}{l}9 \\
(1.5-18)\end{array}$ & $\begin{array}{l}12 \\
(6-16)\end{array}$ \\
\hline Gender & $\%$ male & $33 \%$ & $63 \%$ & $57 \%$ & $40 \%$ \\
\hline Tonsillar descent & $\begin{array}{l}\text { Mm - mean } \\
\text { and range }\end{array}$ & $\begin{array}{l}9.5 \\
(5-20)\end{array}$ & $\begin{array}{l}11 \\
(5-14)\end{array}$ & $\begin{array}{l}12 \\
(5-20)\end{array}$ & $\begin{array}{l}14 \\
(5-34)\end{array}$ \\
\hline $\begin{array}{l}\text { Symptoms } \\
\text { Headaches } \\
\text { Weakness } \\
\text { Paresthesias } \\
\text { Bulbar } \\
\text { Scoliosis }\end{array}$ & $\mathrm{N}$ & $\begin{array}{l}3 \\
0 \\
0 \\
0 \\
1\end{array}$ & $\begin{array}{l}3 \\
5 \\
0 \\
1 \\
1\end{array}$ & $\begin{array}{l}6 \\
5 \\
0 \\
1 \\
2\end{array}$ & $\begin{array}{l}5 \\
0 * \\
2 \\
3 \\
8 *\end{array}$ \\
\hline $\begin{array}{l}\text { Normal } \\
\text { electrophysiology^ }\end{array}$ & $\mathrm{N}$ & 1 & 4 & 5 & $8 *$ \\
\hline
\end{tabular}

* Significantly different by $\chi^{2}$ analysis at the 0.05 level of significance;

$\wedge$ Electrophysiology includes brainstem auditory evoked potentials

(BAEP) and somatosensory evoked potentials (SSEP) 
Table 2: Study patient outcomes following selected therapy

\begin{tabular}{|c|c|c|c|}
\hline & Group A & Group B & Group C \\
\hline $\begin{array}{l}\text { Posterior fossa } \\
\text { decompression }\end{array}$ & 6 & 6 & 5 \\
\hline $\begin{array}{l}\text { Posterior fossa } \\
\text { decompression with } \\
\text { duraplasty }\end{array}$ & 0 & 2 & 5 \\
\hline $\begin{array}{l}\text { Intraoperative } \\
\text { ultrasound }\end{array}$ & $\begin{array}{l}\text { Performed in } \\
3 \text {, good flow }\end{array}$ & $\begin{array}{l}\text { Performed in } \\
7,2 \text { abnormal } \\
\text { motivating } \\
\text { duraplasty }\end{array}$ & $\begin{array}{l}\text { Performed in } 9 \text {, } \\
\text { good flow in } 5 \text { in } \\
\text { whom only } \\
\text { posterior fossa } \\
\text { decompression } \\
\text { performed }\end{array}$ \\
\hline \multicolumn{4}{|l|}{ Outcome } \\
\hline Clinical & Improved & Improved & Improved \\
\hline Radiological & $\begin{array}{l}\text { Improved } \\
\text { scoliosis in } 2\end{array}$ & $\begin{array}{l}\text { Tonsillar } \\
\text { ascent in } 2\end{array}$ & $\begin{array}{l}\text { Syrinx decrease in } \\
4 \text { and resolution in } \\
3 \\
\text { Remaining } 3 \\
\text { patients underwent } \\
\text { second operation } \\
\text { yielding syrinx } \\
\text { resolution }\end{array}$ \\
\hline Electrophysiological & Improved & Improved & Improved \\
\hline
\end{tabular}

subarachnoid shunt, for failure of the syrinx to resolve. All ten patients eventually experienced symptomatic improvement and improvement in the syrinx configuration.

These treatment outcomes are summarized in Table 2, with all 24 patients exhibiting symptomatic improvement. The 19 patients who were treated in accordance with the proposed algorithm experienced clinical improvement without further intervention. By contrast, three $(60 \%)$ of the five patients who were treated more conservatively than by the proposed algorithm required a secondary operation to achieve adequate syrinx resolution ( $\chi^{2}$ test with William's correction, $\alpha=0.05$ ).

\section{Discussion}

The more widespread availability of contemporary neuroimaging techniques, particularly advanced magnetic resonance imaging techniques, has permitted more rigorous evaluation of both static and dynamic anatomy of the cervicomedullary junction in patients with Chiari I malformation. The structural features of cisterna magna anatomy, extent of tonsillar descent, and presence of a spinal syrinx provide insight into the magnitude of decompression required and operative techniques indicated to achieve such decompression, as may the physiological features of CSF space anterior and posterior to the neural elements at the level of the foramen magnum with no impediment of flow. ${ }^{11}$ Consistent responses in surveys of attending neurosurgeons supports the treatment of symptomatic patients, although the specific surgical techniques beyond the decompressive suboccipital craniectomy remain inconsistent..$^{21,22}$ Utilization of duraplasty is generally supported, despite a growing body of evidence suggesting higher likelihood of complications, most commonly infections and CSF leak. ${ }^{10,11,14}$
The heterogeneity of preoperative and intraoperative findings in Chiari I malformations draws into question the attitude of delivering the same operation to each patient. Selection among different procedures is complicated by the fact that no randomized trial to date has compared the efficacy of even the two most utilized techniques: suboccipital decompression with or without duraplasty. The method of greatest consensus among neurosurgeons, suboccipital decompression with duraplasty and potentially other intradural manipulation, ${ }^{21,22}$ has accumulated evidence of good overall outcomes. ${ }^{13,30,32-34}$ Conversely, among appropriately selected patients, a trend toward more conservative surgery has gained support. Caldarelli and coworkers ${ }^{7}$ describe purely extradural approach for 30 pediatric patients, of whom all experienced symptomatic resolution although $50 \%$ of those patients with syringomyelia exhibited no change in the lesion size. Genitori et $\mathrm{al}^{8}$ provide similar evidence of how such minimal intervention yields clinical improvement in 16 of 16 patients with brainstem compression and 8 of 10 patients with syringomyelia.

However, it is important to understand if certain patients could benefit from more limited operation with bony decompression alone to protect them from risk of more invasive operation, as well as those in whom duraplasty is required. This question is most frequently addressed by dichotomous stratification of surgical approach. Limonadi and Selden ${ }^{9}$ and Navarro and coworkers ${ }^{10}$ use the presence of a syrinx as the defining feature to follow bony decompression with duraplasty instead of dural splitting, and both report similar clinical outcomes between groups. Recent retrospective work by Attenello et $\mathrm{al}^{27}$ suggests that improvement of symptomatic Chiari I malformation patients with syringomyelia is irrespective of duraplasty, however only three of their 39 patients were decompressed without duraplasty rendering such conclusion spurious. More recent work by the same group suggests that the composition of the duraplasty material, favoring polytetrafluoroethylene over pericranium, may enhance both clinical and radiographic syrinx and posterior fossa configuration improvement. ${ }^{12}$ A recent meta-analysis of the role of duraplasty in the treatment of symptomatic Chiari I malformations, composed of five retrospective and two prospective cohort studies, suggests that decrease in syrinx size occurs in $87 \%$ of patients treated with suboccipital decompression and duraplasty and only $56.3 \%$ of patients treated with suboccipital decompression alone, although there was no standardization of selection between operative approaches and choice was primarily motivated by surgeon preference. ${ }^{13}$

An alternate method of selecting among patients in whom duraplasty may be required is through the use of intraoperative ultrasound findings of persistent compression, absence of sufficient CSF space, or inadequate CSF flow. In a retrospective analysis of intraoperative ultrasonography to evaluate adequacy of subarachnoid spaces, McGirt et $\mathrm{al}^{30}$ describe utility in the setting of tonsillar ectopia rostral to $\mathrm{C} 1$ with no difference in outcomes for patients treated with craniectomy or additional duraplasty. However, their patients exhibited $70 \%$ higher relative likelihood of symptom recurrence with tonsillar descent beyond $\mathrm{C} 1$ when duraplasty is not performed, suggesting a more limited role for ultrasonographic evaluation in this context. A shortcoming is that other anatomical features such as the 
presence of spinal cord syrinx were not evaluated in that analysis. Yeh and coworkers ${ }^{11}$ applied intraoperative ultrasonography findings of inadequate CSF volume or abnormal tonsillar pistoning to include duraplasty and tonsillar shrinkage in addition to suboccipital decompression. Successful outcome was achieved in over $95 \%$ of all 124 patients, of whom 85 underwent the more extensive procedure, and the stated differences between treatment groups were of prolonged hospital stay and greater minor perioperative morbidity of headache, nausea, and pain. Further extension to standardize such techniques have been proposed to decompress the cervicomedullary junction, create a retrocerebellar space of between 8 and $10 \mathrm{~cm}^{3}$ volume, and to confirm flow between the cranial and spinal CSF compartments. ${ }^{31}$ These authors define the optimal flow characteristics as peak velocity of between 3 and 5 $\mathrm{cm} / \mathrm{s}$, bidirectional movement, and exhibition of vascular and respiratory variations. Prospective validation of these volumetric and flow parameters remain to be seen.

We see this spectrum of clinical presentation, neuroimaging findings, and surgical outcomes as revealing a hierarchy of changes, spanning from the initial anatomic derangements of small posterior fossa and tonsillar ecotopia, to altered CSF flow and obliteration of CSF spaces at the craniovertebral junction, to the pathological changes of spinal canal expansion and syrinx formation. While the specific pathophysiology responsible for progression between these states remains uncertain and disputed, their identification by preoperative neuroimaging and further stratification by intraoperative ultrasonography provides for convenient classification to help guide treatment. We propose that those patients with spinal cord syrinx (Group C) or those with abnormal intraoperative ultrasound after posterior fossa decompression (Group B, abnormal ultrasound) require both bony decompression and duraplasty. Conversely, those patients with milder structural pathology (Group A) or adequate space after posterior fossa decompression (Group B, normal ultrasound) may be treated less aggressively. Such an algorithm is fundamentally based on establishing sufficient CSF flow at the craniovertebral junction using the minimum of surgical manipulation required to achieve that objective. In this retrospective review, all of the 19 patients treated in accordance with this algorithm exhibited clinical and radiographic improvement, whereas $60 \%$ of those Group C patients treated with suboccipital craniectomy and laminectomy only required a second operation to more definitely address the syrinx. It is well known that patients with syringomyelia can exhibit improvement with entirely extradural decompression, ${ }^{8,9,35}$ though substantially greater uniform success was noted among our syrinx patients following the more definitive posterior fossa decompression with duraplasty.

A complicating feature is the recent description of a presyrinx state that may represent a reversible state of disordered CSF flow dynamics, known to potentially progress to a cavitating lesion, ${ }^{36}$ hence blurring the boundary between Groups A and B versus Group C. The MRI characteristics of these lesions are of T2 prolongation, mild T1 prolongation, and cord enlargement without frank cavitation. ${ }^{37}$ Patients with such pathology may more appropriately uniformly require aggressive decompression including duraplasty, though this entity was not observed among those patients treated over the course of this study.

\section{LIMITATIONS}

The small number of patients included in this retrospective work was to perform a preliminary exploration of a proposed algorithm to guide surgical judgment. While patients treated in accordance with the recommendation did experience improved clinical outcomes, the utility of this tool must be compared for both success and complication against a group of patients without such tailored treatment. The development of this algorithm was motivated by reported practice patterns and institutional guidelines, and certainly the validity of such a tool is best evaluated when applied to an independent and larger sample of patients in a prospective and multicenter fashion. Further, while less frequently utilized techniques such as tonsillar resection or shrinkage were not applied in this work, these represent additions to the minimum guidelines advocated here and should be indicated by patient pathoanatomy.

\section{Conclusions}

This study introduces a treatment algorithm by which the surgical treatment of symptomatic Chiari I malformation may be standardized. Preliminary retrospective application of this treatment scale to 24 patients who have been treated at $\mathrm{CHEO}$ reveals excellent clinical outcome, and, where applicable, radiographic resolution of the spinal cord syrinx. Group A patients in whom there is no spinal cord syrinx and in whom a cistern magna can be visualized on preoperative neuroimaging uniformly benefited from suboccipital decompression only. Group B patients in whom there is no spinal cord syrinx and in whom a cistern magna cannot be visualized on preoperative neuroimaging have their treatment tailored by intraoperative ultrasound findings, with duraplasty indicated when this study reveals inadequate CSF volume or flow, again uniformly benefiting from this algorithm. Group $\mathrm{C}$ patients in whom a spinal cord syrinx is present should undergo both with the goal of achieving symptomatic resolution and treating the underlying syrinx pathophysiology. Validation of this algorithm as a clinical tool will require prospective evaluation of a larger patient population across multiple centers.

\section{REFERENCES}

1. Chiari H. Uber Veranderungen des Kleinhirins infolge von Hydrocephalie des Grosshirns. Dtsch Med Wochenshr. 1891;17: 1172-5.

2. Nishikawa M, Sakamoto H, Hakuba A, Nakanishi N, Inoue Y. Pathogenesis of Chiari malformation: a morphometric study of the posterior cranial fossa. J Neurosurg. 1997;86(1):40-7.

3. Prassopoulos P, Cavouras D, Golfinopoulos S. Developmental changes in the posterior cranial fossa of children studied by CT. Neuroradiology. 1996;38(1):80-3.

4. Sekula RF, Jr., Jannetta PJ, Casey KF, Marchan EM, Sekula LK, McCrady CS. Dimensions of the posterior fossa in patients symptomatic for Chiari I malformation but without cerebellar tonsillar descent. Cerebrospinal Fluid Res. 2005;2:11.

5. Sgouros S, Kountouri M, Natarajan K. Posterior fossa volume in children with Chiari malformation Type I. J Neurosurg. 2006; 105 Suppl 2:101-6.

6. Trigylidas T, Baronia B, Vassilyadi M, Ventureyra EC. Posterior fossa dimension and volume estimates in pediatric patients with Chiari I malformations. Childs Nerv Syst. 2008;24(3):329-36.

7. Caldarelli M, Novegno F, Vassimi L, Romani R, Tamburrini G, Di Rocco $\mathrm{C}$. The role of limited posterior fossa craniectomy in the surgical treatment of Chiari malformation Type I: experience with a pediatric series. J Neurosurg. 2007;106 Suppl 3:187-95. 
8. Genitori L, Peretta P, Nurisso C, Macinante L, Mussa F. Chiari type I anomalies in children and adolescents: minimally invasive management in a series of 53 cases. Childs Nerv Syst. 2000;16 (10-11):707-18.

9. Limonadi FM, Selden NR. Dura-splitting decompression of the craniocervical junction: reduced operative time, hospital stay, and cost with equivalent early outcome. J Neurosurg. 2004;101 Suppl 2:184-8.

10. Navarro R, Olavarria G, Seshadri R, Gonzales-Portillo G, McLone DG, Tomita T. Surgical results of posterior fossa decompression for patients with Chiari I malformation. Childs Nerv Syst. 2004; 20(5):349-56.

11. Yeh DD, Koch B, Crone KR. Intraoperative ultrasonography used to determine the extent of surgery necessary during posterior fossa decompression in children with Chiari malformation type I. J Neurosurg. 2006;105 Suppl 1:26-32.

12. Attenello FJ, McGirt MJ, Garces-Ambrossi GL, Chaichana KL, Carson B, Jallo GI. Suboccipital decompression for Chiari I malformation: outcome comparison of duraplasty with expanded polytetrafluoroethylene dural substitute versus pericranial autograft. Childs Nerv Syst. 2009;25(2):183-90.

13. Durham SR, Fjeld-Olenec K. Comparison of posterior fossa decompression with and without duraplasty for the surgical treatment of Chiari malformation Type I in pediatric patients: a meta-analysis. J Neurosurg Pediatrics. 2008;2(1):42-9.

14. Munshi I, Frim D, Stine-Reyes R, Weir BK, Hekmatpanah J, Brown F. Effects of posterior fossa decompression with and without duraplasty on Chiari malformation-associated hydromyelia. Neurosurgery. 2000;46(6):1384-9; discussion 89-90.

15. Klekamp J, Batzdorf U, Samii M, Bothe HW. The surgical treatment of Chiari I malformation. Acta Neurochir (Wien). 1996;138(7):788-801.

16. Hida K, Iwasaki Y. Syringosubarachnoid shunt for syringomyelia associated with Chiari I malformation. Neurosurg Focus. 2001; 11(1):E7.

17. Iwasaki Y, Hida K, Koyanagi I, Abe H. Reevaluation of syringosubarachnoid shunt for syringomyelia with Chiari malformation. Neurosurgery. 2000;46(2):407-12; discussion 12-13.

18. Bindal AK, Dunsker SB, Tew JM, Jr. Chiari I malformation: classification and management. Neurosurgery. 1995;37(6): 1069-74.

19. Sahuquillo J, Rubio E, Poca MA, Rovira A, Rodriguez-Baeza A, Cervera C. Posterior fossa reconstruction: a surgical technique for the treatment of Chiari I malformation and Chiari I/syringomyelia complex--preliminary results and magnetic resonance imaging quantitative assessment of hindbrain migration. Neurosurgery. 1994;35(5):874-84; discussion 84-5.

20. Sakamoto H, Nishikawa M, Hakuba A, Yasui T, Kitano S, Nakanishi N, et al. Expansive suboccipital cranioplasty for the treatment of syringomyelia associated with Chiari malformation. Acta Neurochir (Wien). 1999;141(9):949-60; discussion 60-1.

21. Schijman E, Steinbok P. International survey on the management of Chiari I malformation and syringomyelia. Childs Nerv Syst. 2004; 20(5):341-8.

22. Haroun RI, Guarnieri M, Meadow JJ, Kraut M, Carson BS. Current opinions for the treatment of syringomyelia and chiari malformations: survey of the Pediatric Section of the American Association of Neurological Surgeons. Pediatr Neurosurg. 2000; 33(6):311-7.

23. Krieger MD, McComb JG, Levy ML. Toward a simpler surgical management of Chiari I malformation in a pediatric population. Pediatr Neurosurg. 1999;30(3):113-21.

24. Dyste GN, Menezes AH, VanGilder JC. Symptomatic Chiari malformations. An analysis of presentation, management, and long-term outcome. J Neurosurg. 1989;71(2):159-68.

25. Levine DN. The pathogenesis of syringomyelia associated with lesions at the foramen magnum: a critical review of existing theories and proposal of a new hypothesis. J Neurol Sci. 2004; 220(1-2):3-21.

26. Ventureyra EC, Aziz HA, Vassilyadi M. The role of cine flow MRI in children with Chiari I malformation. Childs Nerv Syst. 2003; 19(2):109-13
27. Attenello FJ, McGirt MJ, Gathinji M, Datoo G, Atiba A, Weingart $\mathrm{J}$, et al. Outcome of Chiari-associated syringomyelia after hindbrain decompression in children: analysis of 49 consecutive cases. Neurosurgery. 2008;62(6):1307-13; discussion 13.

28. Feldstein NA, Choudhri TF. Management of Chiari I malformations with holocord syringohydromyelia. Pediatr Neurosurg. 1999;31 (3):143-9.

29. Park JK, Gleason PL, Madsen JR, Goumnerova LC, Scott RM. Presentation and management of Chiari I malformation in children. Pediatr Neurosurg. 1997;26(4):190-6.

30. McGirt MJ, Attenello FJ, Datoo G, Gathinji M, Atiba A, Weingart $\mathrm{JD}$, et al. Intraoperative ultrasonography as a guide to patient selection for duraplasty after suboccipital decompression in children with Chiari malformation Type I. J Neurosurg Pediatrics. 2008;2(1):52-7.

31. Milhorat TH, Bolognese PA. Tailored operative technique for Chiari type I malformation using intraoperative color Doppler ultrasonography. Neurosurgery. 2003;53(4):899-905; discussion 905-6.

32. Alzate JC, Kothbauer KF, Jallo GI, Epstein FJ. Treatment of Chiari I malformation in patients with and without syringomyelia: a consecutive series of 66 cases. Neurosurg Focus. 2001;11(1):E3.

33. Galarza M, Sood S, Ham S. Relevance of surgical strategies for the management of pediatric Chiari type I malformation. Childs Nerv Syst. 2007;23(6):691-6.

34. Hoffman CE, Souweidane MM. Cerebrospinal fluid-related complications with autologous duraplasty and arachnoid sparing in type I Chiari malformation. Neurosurgery. 2008;62(3 Suppl 1):156-60; discussion 60-1.

35. Hayhurst C, Richards O, Zaki H, Findlay G, Pigott TJ. Hindbrain decompression for Chiari-syringomyelia complex: an outcome analysis comparing surgical techniques. Br J Neurosurg. 2008; 22(1):86-91.

36. Lipson AC, Ellenbogen RG, Avellino AM. Radiographic formation and progression of cervical syringomyelia in a child with untreated Chiari I malformation. Pediatr Neurosurg. 2008;44(3): 221-3.

37. Goh S, Bottrell CL, Aiken AH, Dillon WP, Wu YW. Presyrinx in children with Chiari malformations. Neurology. 2008;71(5): 351-6. 